3

\title{
ENUNCIACIÓN, EXPECTACIÓN Y NARRATIVAS AUDIOVISUALES*
}

DENOMINACIÓN DEL PROYECTO: RECORRIDOS NARRATIVOS Y APROPIACIONES DE LA MIRADA EN TEXTOS VERBALES Y AUDIOVISIVOS

\author{
"El cine, con sus medios, parece pues \\ el espejo ideal de la complejidad dialéctica \\ de los acontecimientos en la plenitud de su representación, \\ en el acto de la cual hay un profundo momento en que \\ el espectador mismo está llamado a participar del proceso creativo."
}

Vsevolod Pudovkin 


\section{O. CUESTIONES INTRODUCTORIAS}

0.1. Las modificaciones que hoy se advierten en la construcción de las imágenes audiovisuales no hacen sino referenciar otros cambios, más generales y profundos, que se han operado en las condiciones mismas de producción, circulación y consumo de los bienes socioculturales.

Desde las simulaciones tecnológicas hasta la fragmentación espectacular de lo político (memorias, simulacros, ficciones, nuevos mitos incluidos), contribuyeron a la desterritorialización y borramiento de las fronteras visibles entre razón e imaginación, ciencia y creatividad, naturaleza y artificio, conocimiento e información.

Porque tal vez las que hayan cambiado sean en realidad las formas o maneras: de dialogar, de encontrarse, de comprender, de analizar, de mirar. Con lo que podría así corroborarse la hipótesis de Augé (1998) según la cual las vinculaciones "de los seres humanos con lo real se modifican por el efecto de representaciones asociadas con las tecnologías, la globalización, la aceleración de la historia".

Por lo que quizás también podría llegar a entenderse que los soportes tecnológicos hubieran naturalizado las representaciones audiovisuales hasta el extremo de convertirlas en exclusivos indicios presentificadores de otra actividad: la actividad audiovisiva misma, en algún sentido más perceptible que lo audiovisible-real.

¿Abducción, mera conjetura? La mirada espectatorial, tan perezosa y domesticable como cualquier otro hábito o rutina, pareciera por momentos preferir el ordenamiento relativamente inteligible y estable de un campo audiovisual pre-seleccionado, en vez de proyectarse por el caótico e ilimitado horizonte del espacio (real) circundante.

0.2. Sin querer solapar las numerosas condicionantes de esta singular mirada actual sobre la cuestión, ni sus alcances e implicaciones ideológicas, ni la evaluación de los paradigmas socioculturales en que unas y otras se sustentan (aunque seguramente aportando, desde otro ángulo reflexivo, a los mismos fines), este prediseño sólo pretende proyectar la captación y descripción de algunos principales modos y procedimientos, dispositivos y estrategias de "esa" representación audiovisual. 
Dicho de otro modo: este primer esbozo intentará aproximarse a la manera en que se construye la función representativa de la poderosa maquinaria del mirar, del ver, del mostrar, tal como se evidencia en algunas manifestaciones (discursivas, textuales) de nuestra cultura. Proyectándolas incluso en relación (comparativa, asociativa o diferencial) con otras (manifestaciones): por caso, las historias, los relatos y las narrativas ${ }^{1}$ verbales / audiovisuales.

Haciéndolo así se procura superar (al menos: posicionarse y tomar distancia de) ciertas dicotomías o polaridades frecuentadas por la teoría, que a menudo revitalizan algún recurrente planteamiento paradójico acerca de esta cuestión: el de la parábola de quien ve la luna y/o de quien ve (primero) el dedo que la señala².

Es decir, por un lado: los defensores de la transparencia del registro icónico, concebido como mimético o reproductivo de una realidad recortada por un marco que la encuadra. Por el otro: los que postulan un trabajo textual hipercodificado, manipulatorio sin concesiones, de un repertorio de unidades significativas organizadas en sistemas y dispuestas conforme con un determinado orden de representación (Bettendorff-Prestigiacomo, 1997: 12).

0.3. La perspectiva aquí elegida (para efectuar un abordaje equidistante de tales extremos) se multidimensiona sin embargo en nuevos entramados problemáticos, que se irán explicitando y profundizando en desarrollos ulteriores de este proyecto: los espacios de la producción (de la enunciación textual) y

${ }^{1}$ El constructo narrativa será conceptualizado, al menos en esta fase inicial de la investigación en curso, como dimensión operativa resultante de tres instancias diferenciales de un mismo proceso (narracional): articulándose, en síntesis, entre la diégesis, el relato, y la narratividad misma... Se entenderá por diégesis o historia el conjunto de acontecimientos, lugares, personajes, etc. exhibidos o implícitos que constituyen la base del relato (el significado vehiculizado por la novela, el film, etc). El conjunto significante, o sea todo lo visible y audible puesto en pantalla (por ejemplo), constituirá el texto o relato fílmico; así como por narración cinematográfica se concebirá al mismo acto de producción del discurso fílmico, indispensable para poner en escena determinada diégesis o historia a través de un relato determinado.

2 "Si la cultura es menos el paisaje que vemos que la mirada con que lo vemos, uno empieza a sospechar que el alegato habla menos de [las imágenes audiovisuales] que de la mirada radicalmente decepcionada de [quien las piensa]" (Barbero-Rey, 1999: 15). 
de la recepción (de la percepción o expectación audiovisual), a su vez sobrestructuradas (sobredeterminadas) por una particular concepción de narrativa ${ }^{3}$ (que sólo en principio será entendida, según nuestra propuesta, como forma constitutiva de toda construcción textual).

Aquellos desenvolvimientos posteriores casi seguramente permitirán diversificar el repertorio de categorías analíticas e interpretativas por sistematizar (recién entonces), a las que habrá de concedérseles una privilegiada atención en el progresivo desarrollo de la propuesta investigativa. Tanto en la reflexión teórica que habrá de sustentarla, como en las mismas praxis de lecturas (aplicadas a textos verbales y audiovisuales) del corpus analítico por constituir.

En cada caso se dará cuenta a la vez de otras convenciones, codificaciones y analogías constituyentes. Incluso, de otras posibles estructuras homologables a (o con) otros sistemas semióticos (el teatro, la literatura, por caso); además de las propias constantes per(re)ceptivas que solemos ejercitar en nuestra cotidiana relación con "lo real" (lo verosímil, el mundo realizable).

El secuenciado tratamiento de unas y otras problemáticas irá insinuando seguramente nuevas aperturas hacia un complejo dominio de investigaciones, en relación con el cual este diseño (lo digo una vez más) sólo pretende constituirse en incipiente fase inicial.

\footnotetext{
${ }^{3}$ Este planteamiento problemático global parte de reconsiderar la tipología textual básica que establece la Lingüística Textual: texto descriptivo, expositivo, argumentativo, instruccional o directivo, y narrativo, relacionado cada tipo textual con diferentes actividades cognitivas. Aun aceptando (con las reservas y cautelas que implica toda extrapolación conceptual de un sistema semiótico a otro) el predominio de las categorías descriptiva y narrativa como dominantes más o menos equivalentes en el texto audiovisual, se habrá de postular aquí lo narracional como dimensión supraestructural o hegemónica de dicha textualidad audiovisiva. La imagen, aunque sólo fuera de naturaleza espacial, ha procurado captar desde siempre (cf. las pinturas rupestres) el fluir temporal: rasgo estructurante específico de toda construcción narrativa. Con mayor razón y evidencia, entonces, las imágenes propiamente audiovisuales. Al recuperar las tres dimensiones temporales en su observación y mostración de una realidad significada (presentificación de lo mostrado, activación de la memoria y expectativa de la mirada), las representaciones audiovisuales se organizan como producto (relato) de un proceso significante (producción narrativa): inmediatez de la expectación, reposición de lo pasado, promesa/anuncio de futuro.
} 


\section{RESUMEN DEL PROYECTO}

El presente proyecto se propone indagar en los soportes estructurales básicos que identifican a los denominados discursos audiovisuales, mediante el abordaje de sus principales dispositivos textuales y algunas de las estrategias narrativas, enunciativas y perceptivas que los caracterizan. Desde esta perspectiva semiótica se pretende contribuir a una mejor explicación y comprensión del objeto/problema y sus modos de funcionamiento, profundizar en los efectos de sentido que construyen una singular mirada espectatorial en tales manifestaciones, y formalizar en lo posible determinados principios constitutivos y rasgos diferenciales que permitan significar un aporte al esclarecimiento de la especificidad audiovisual.

La propuesta quisiera desarrollarse, en su primer tramo, a partir de un trabajo crítico de relevamiento documental y transposición teórico-metodológica de nociones y categorías procedentes de diferentes dominios afines: la semiótica discursiva y textual, la lingüística de la enunciación, las narratologías literaria y fílmica... Dicha tarea previa estará destinada a producir un corpus selectivo y combinatorio de dimensiones y variables analíticas e interpretativas, en cualquier caso relacionadas con actividades y representaciones narrativas, enunciativas y re(per)ceptivas (consideradas en principio como) igualmente propias y/o características de los discursos verbales o audiovisuales. Desde este lineamiento inicial, aspira a proyectarse hacia su ulterior propósito de indagar en algunas matrices de especificidad formal correspondientes a unos y otros lenguajes.

Confrontando en definitiva teorías y operatorias (en ambos casos aplicadas a la lectura descriptiva, explicativa y comprensiva de los distintos relatos verbales y audiovisuales que compondrán el respectivo corpus analítico), la primera fase del proyecto procurará dar cuenta de las transgresiones y diversificaciones supuestas por cada diferente mirada o asedio textual. En un segundo momento, intentará justificar la necesidad de reconceptualizar los constructos en cuestión, antes de efectuar cualquier otro intento de reformulación, subclasificación genérica, nueva tipologización discursiva o textual, etc. 


\section{SITUACIÓN MOTIVADORA}

Las anteriores proposiciones tentativas no pretenden solapar, como ya se dijo, la naturaleza pluridimensional del discurso/objeto audiovisual, ni descartar o excluir otros postulados e intereses (sociales, ideológicos, estéticos, industriales, etc.) que, también inscriptos en su textura comunicacional y significativa, pudieran caracterizar posibles modos de producción, circulación y consumo.

Sin embargo, por considerar al dispositivo audiovisual como componente de un sistema discursivo y narrativo de producción significante (es decir: al pensarlo a la vez como lugar y proceso de interrelaciones del sentido y la significación, y como síntesis y síncresis de lenguajes diversos: en consecuencia, como susceptible de variadas prácticas de decodificación-interpretación), este diseño de investigación privilegia la perspectiva semiótica en el abordaje de su objeto de estudio.

Posicionándose así en previsiones y cautelas analíticas o explicativas de dicha perspectiva semiótica, e incorporando contribuciones de determinados enfoques teóricos y metodológicos (del propio campo disciplinar u otros dominios afines $)^{4}$, resultará posible avanzar progresivamente en la construcción de nuevos supuestos e hipótesis y operar sucesivos recortes en la temática inicial. Esto es: desde la reflexión sobre los procesos de apropiación/configuración (narrativa, enunciativa, re(per)ceptiva)... hacia su confrontación en prácticas de lectura aplicadas a un corpus diversificado de textos verbales y audiovisuales, atendiendo (en cada caso) a las características y componentes propias de cada especificidad discursiva.

Asimismo, la temática de este proyecto se constituye como segmento intercalar de un tramo investigativo mayor, que se propone indagar en la construcción semionarrativa y discursiva del denominado cine documental y/o de divulgación científica y en sus posibles modos de abordaje, transposición y

\footnotetext{
${ }^{4}$ Unas y otras formulaciones del referido contexto teórico-explicativo permitirían fundar esta idea constructiva de relato que postula el proyecto (cf. notas 1 y 3), concebido como proceso generativo textual que sólo puede ser comprendido e interpretado si se lo acompaña en su recorrido y se lo aborda, con una mirada integradora, en su dualidad de acontecer narrado y de forma de ser contado. Esto es: identificando los diferentes códigos que se implican en su funcionamiento, y estableciendo entre ellos las relaciones que manifiestan la polifonía textual que soporta y constituye la estructura narrativa del relato en cuestión.
} 
aprovechamiento didáctico ${ }^{5}$. Por lo tanto, los insumos producidos en el marco del presente subproyecto permitirán aportar explicitación de supuestos, delimitación de dispositivos y estrategias, categorización de dimensiones y variables analíticas e interpretativas, etc., respecto de aquel otro objeto de estudio englobante. Andamiar, en definitiva, la constitución de específicos parámetros para su (simultáneo o posterior) tratamiento y problematización.

\section{ANTECEDENTES SOBRE EL TEMA}

Esta propuesta investigativa surge de reconocer el inusitado interés que ha despertado en los últimos años el estudio sobre las problemáticas enunciativas, espectatoriales y narrativas (así como la importancia de los aportes efectuados) en el dominio de los análisis discursivos y textuales aplicados al campo audiovisual ${ }^{6}$.

Al ponderar sin embargo, en el tramo inicial de su ejecución, la tarea de relevamiento y sistematización de contribuciones previas, es porque se quiere advertir acerca de ciertas carencias o insuficiencias detectadas y la persistencia de zonas de vacancia en el dominio en cuestión 7 , a pesar de aquella motivación y de la profusa bibliografía existente al respecto.

Cabe aclarar, por una parte, que las cuestiones en tratamiento han sido casi siempre aplicadas, de manera prácticamente excluyente, a textos y discursos televisivos o cinematográficos. Asimismo, que muchas veces han generado

${ }^{5} \mathrm{Cfr}$. al respecto el Cuaderno No 1 de esta misma serie: Travesías del sentido / Indagaciones narrativas; especialmente el apartado "2.3. Travesías del documental") .Qué es un film documental, cuál es su especificidad constitutiva y genérica en el contexto de las narrativas audiovisuales; de qué manera construye sus significados (representa y/o resignifica objetos, aspectos o comportamientos de la realidad); a partir de qué supuestos sería posible tipologizarlo; cómo puede ser leído, descripto e interpretado, y (a la vez) mejor aprovechado en concretas situaciones de enseñanza y de aprendizaje escolar..., se nos aparecen (inicialmente) como interrogaciones centrales de una motivadora y productiva propuesta de investigación y desarrollo. (Caudana, 2004: 62).

${ }^{6} \mathrm{Cfr}$. nómina de textos iniciales de consulta y de apoyatura teórico-metodológica en las "Referencias bibliográficas", al final de este diseño investigativo.

${ }^{7} \mathrm{Cfr}$. asimismo nuestros propios avances en líneas afines de investigación del dominio, desarrollados en diferentes tramos del Proyecto de Semiótica (1991-2003). 
crecimientos desordenados e innecesarias complejidades, para una acabada comprensión de sus formulaciones teóricas y metodológicas, o un más redituable aprovechamiento de sus praxis analíticas e interpretativas.

Por otro lado (diferenciándose en esto de los estudios narratológicos aplicados al ámbito literario por ejemplo), en el campo audiovisual suelen plantearse dimensiones o variables de tipo general, y sólo eventualmente precisas categorías teóricas o analíticas, ejemplificándoselas apenas con algunas situaciones o fragmentos fílmicos. Igualmente, son escasas las lecturas aplicadas al nivel enunciativo de un texto audiovisual, y aun menos frecuente indagar sobre efectos de sentido producidos por una "propuesta enunciativa global" (Steimberg, 1993; Tassara, 2001).

Otro criterio o enfoque, finalmente, sin pretensión de agotar con esto las restricciones posibles... A la vez que apreciar su singular naturaleza de imagen en movimiento, procediendo a la manera de los demás trabajos teóricos o ya aplicados al campo, este emprendimiento nuestro presupondrá que el enunciado audiovisual también relata mediante la conformación de dispositivos y soportes que ponen en juego complejos entramados de sustancias y/o materias diversas del plano de la expresión audiovisual.

\section{AVANCES EN LA FUNDAMENTACIÓN}

4.1. El diseño de este proyecto parte en consecuencia de un conjunto de supuestos motivados en (o por) respuestas provisionales, tentativas u ocasionales, formuladas a propósito de numerosas interrogantes iniciales. Entre otros presupuestos básicos, se puede establecer que:

$>$ A través de diferentes recorridos teóricos y analíticos, aplicados a la lectura de textos verbales y audiovisuales, es posible reconocer distintos procesos semiósicos de apropiación y configuración del sentido.

$>$ Dichos procesos semiósicos sólo pueden ser diferenciados a condición de que se atiendan las características propias de la discursividad verbal y audiovisual, la estructuración de sus soportes técnicos y la configuración de sus dispositivos textuales específicos. 
$>$ Dadas aún por (pre)supuestas estas analogías, similitudes o diferencias entre textualidades diversas, también en la elaboración de un texto audiovisual operarían distintas componentes formales y temáticas organizadas según precisas estrategias destinadas a actualizar la doble competencia a actualizar la doble competencia perceptivo-cognoscitiva del espectador (esto es: a construir el recorrido de su mirada). > Para avanzar y profundizar en estas y otras posibles implicaciones de la propuesta, será necesario reconceptualizar dimensiones, variables y categorías de los constructos narración, enunciación y per(re)cepción, aplicados al campo textual en general y audiovisual en particular.

4.2. Ante el interrogante de por dónde comenzar a desarrollar y resolver estas cuestiones relacionadas con la enunciación, la expectación y la narración audiovisual, aquellos iniciales lineamientos fundamentales reiteran la necesidad de sistematizar, compatibilizar, transponer y (eventualmente) reconceptualizar nociones y categorías analíticas e interpretativas procedentes de diferentes aportes y contribuciones. Por ejemplo:

$>$ De la teoría lingüística de la enunciación, en todo lo relacionado con la configuración de la subjetividad y la actividad representacional de los discursos audiovisuales (las huellas o marcas enunciativas y sus lugares de emergencia, en el tiempo, el espacio y la modalización de los respectivos enunciados fílmicos, televisivos, etc.) ${ }^{8}$; $>$ De los diversos desarrollos de las teorías semióticas y narratológicas, sean éstas aplicadas a la reflexión sobre el pensamiento narrativo ${ }^{9}$, o bien al estudio específico de los textos en general ${ }^{10}, \mathrm{y} / \mathrm{o}$ de los relatos literarios o audiovisuales (cinematográficos) $)^{11}$ en particular.

\footnotetext{
${ }^{8}$ Desde la consideración del aparato formal de la enunciación (Benveniste, 1985), hasta la polifónica delimitación de sus lugares de emergencia (Ducrot, 1986) o su planteamiento como efecto de sentido global (Steimberg, 1993). ${ }^{9}$ Cfr. Bruner, 1997; Larrosa, 1995; McEwan y Egan, 1998; Mumby, 1997; White, 1992; entre otros.

${ }^{10}$ Especialmente, las sucesivas contribuciones de los semiotistas de la Escuela de París (Greimas, Courtés, Fontanille, Rastier, entre otros), y de la Escuela de Tartu (Lotman, Uspenski, Meletinski, etc.).

${ }^{11}$ Se abordarán las diferentes nociones y categorías en cuestión (aparato enunciativo, posiciones narrativas, punto de vista, voz narradora, tipologías, focalizaciones, etc.) confrontando/contrastando aportes de unas y otras teorías narratológicas. Entre otros referentes principales, cfr. por ejemplo Aumont, 1990; Bal, 1998; Betettini, 1986;Casetti, 1989; Gaudreault, 1995; Genette, 1998; Jost, 2002; Steimberg, 1993; Tassara, 2001; Vilches, 1998; Zunzunegui, 1996; etc.
} 
4.3. Al confrontar (re)elaboraciones teóricas y lecturas aplicadas a un corpus diversificado de textos verbales y audiovisuales, interesa en definitiva al proyecto reconocer, analizar e interpretar cómo se constituyen en la práctica los procesos de apropiación y configuración del sentido, atendiendo a las características específicas de cada discursividad. Sin soslayar dichas zonas diferenciales, este abordaje interesado en perspectivas de confrontación demanda no obstante recortar algunos ejes comunes que permitan seleccionar reconocimientos y recorridos iniciales del corpus. En este caso, aquellos lugares de los textos desde donde (unos y otros) son hablados (leídos) productivamente: es decir, en tanto que se constituyen (primero, o a la vez) como hablas (posibilidades de lectura) específicas, singulares.

El espacio de la recepción (de la percepción o expectación) por ejemplo, desde donde incluso lo audiovisual puede ser analizado como reconstrucción de una narrativa: el relato de la mirada del espectador, que consume (consuma y resuelve) pactos estratégicos intervinientes en el diálogo textual... se evidencia como uno de esos lugares específicos. O el espacio de la producción (de la enunciación textual), desde donde también lo audiovisual puede ser reconstituido como otra narrativa de nuevas y diferentes miradas, con selecciones y combinaciones de soportes y dispositivos, imágenes o técnicas operadas durante el rodaje, el montaje.

4.4. Finalmente: a propósito de determinadas matrices de especificidad formal de los textos verbales y audiovisuales, y respecto de la búsqueda de posibles conexiones y diferencias relacionadas con los constructos enunciación y narración, se establecerá una proposición tentativa (prehipótesis) que habrá de regular las primeras comprobaciones del proyecto en desarrollo.

Del planteo del problema, sus principales interrogantes y respuestas provisionales, y de la consulta inicial de antecedentes y postulaciones teóricometodológicas de fundamento, surge con relativa evidencia que así como la lectura del relato verbal privilegia la diversificación de categorías en su instancia narrativa en desmedro de la enunciativa, la percepción espectatorial que supone el relato cinematográfico (en general, audiovisual) enfatiza las competencias enunciativas del filme respecto de sus configuraciones narrativas. 


\section{IMPACTO DE LA PROPUESTA}

Si se consideran la índole singular del objeto de estudio, y aun los espacios de vacancia que sigue presentando un dominio relativamente estabilizado o consolidado como el demarcado, se comprenderá que no puedan mensurarse a priori o calcularse en términos proyectivos los efectos sociales, científicos, económicos, etc. de esta propuesta. Al profundizar y conciliar perspectivas o postulaciones teórico-metodológicas a veces divergentes, que actualmente se debaten e investigan con escasas vinculaciones entre sí, se contribuirá sin embargo a una progresiva superación de la situación existente.

El ejercicio interactivo de permutas e intercambios entre prácticas reflexivas, interpretativas y críticas no sólo permitirá ejemplarizar y expandir una dinámica constructiva esencial al desarrollo del pensamiento semiósico. También podrá generar aportes concretos a las prácticas didácticas e investigativas aplicadas al campo audiovisual, favoreciendo así una acabada comprensión de los fenómenos de transposición discursiva y textual.

La virtual comprobación de que ciertas actividades y efectos narracionales o enunciativos podrían operar como principios constructivos de diferenciación estructural (entre textualidades diversas) permitirá también fundamentar necesarios deslindes acerca de algunas extensiones habituales, al dominio de lo audiovisual, de indagaciones primeramente efectuadas por el campo de la teoría literaria (o a la inversa). Asimismo, posibilitará establecer distintas bases o criterios para categorizar, reconceptualizar o formalizar nuevas clasificaciones, tipologías, etc. a propósito del objeto en cuestión.

\section{ORIENTACIONES METODOLÓGICAS}

6.1. El enfoque metodológico del proyecto articulará tres magnitudes en un mismo proceso investigativo: (a) una dimensión identificadora, de corte epistemológico, ya que se construirá el marco teórico-explicativo a partir de atribuir o reconocer valores singulares a los conceptos y categorías intervinientes, habida cuenta de la índole inter(trans)disciplinaria del objeto de estudio; 
(b) una dimensión estratégica, que permitirá poner en relación contrastativa, sincrónica y dialéctica construcciones discursivas específicas de diferentes disciplinas involucradas, con el propósito de advertir su potencial significante y de reconocerlas mediante prácticas de lectura comprensiva; y (c) una dimensión transformacional, pretendidamente superadora de lo existente, en tanto que se relacionarán nociones y categorías antes contrastadas con propuestas reconstitutivas del objeto, derivándolas de prácticas de indagación aplicadas al análisis e interpretación de textos específicos (verbales y audiovisivos).

6.2. Los procedimientos y técnicas se seleccionarán en función de las distintas fases del proceso de investigación. Los procedimientos descriptivos (protocolos, repertorios y guías de observación) se corresponderán con técnicas tendientes a relevar, clasificar u ordenar las componentes textuales y categorías discursivas. Las instancias no descriptivas serán del tipo teórico-general (respecto de la delimitación o ampliación de dominios) y teórico-particular (en cuanto al marco analítico y las definiciones operacionales). Ocasionalmente se aplicarán también técnicas predictivas y explicativas, además de comprensivas e interpretativas, asociadas a la observación del material constituyente del corpus.

6.3. La tarea investigativa se iniciará, como queda dicho, con un trabajo de relevamiento, análisis y profundización (crítica, recreadora y reconstitutiva) de la información documental y del material bibliográfico disponible, existente en la materia. Partiendo de esta tarea previa se propondrá sistematizar, compatibilizar, transferir, transponer y eventualmente articular nociones y categorías procedentes, en principio, de la semiótica discursiva y textual, de la lingüística de la enunciación, de las narratologías literaria y fílmica.

6.4. Una vez sistematizados los resultados del relevamiento efectuado sobre material bibliográfico y documental, la fase ejecutiva posterior del proyecto se secuenciará en (por lo menos) las siguientes etapas: (a) reorientar los estudios de situación y de factibilidad, avanzando en indagaciones de corte exploratorio; (b) precisar, profundizar y reajustar los iniciales marcos teórico y analítico de la propuesta; (c) seleccionar campos de muestreo y establecer un corpus textual provisorio (cuentos literarios, filmes documentales, etc.); (d) determinar 
instancias definicionales $u$ operacionales de un estudio de casos y formalizar una estructura clasificatoria sobre la construcción de datos; (e) transponer las dimensiones y categorías explicativas e interpretativas al corpus textual analítico y operativo (trabajo de campo); (f) procesar la información obtenida, contrastar hipótesis, validar conclusiones y elaborar indicadores de una nueva versión (proyectual) por ejecutar.

6.5. Se aprecia que el desenvolvimiento del proyecto así enunciado demandar á un máximo de dos años, por lo que las actividades previstas para el desarrollo de cada etapa (cronograma tentativo) se distribuirán según ordenamientos bimestrales o trimestrales. Los progresivos avances y conclusiones parciales obtenidas podrán ser expuestos en congresos, paneles, conferencias, jornadas de comunicación, publicaciones periódicas, etc. y, de manera sistemática, en los Seminarios de investigación semiótica que se cursan en la Facultad de Humanidades y Ciencias de la Universidad Nacional del Litoral. 